OPEN ACCESS

Edited by:

Jiangyue Zhao,

China Medical University, China

Reviewed by:

Han Zhang,

The First Affiliated Hospital of China Medical University, China Mingwu Wang,

University of Arizona, United States

*Correspondence:

Yehong Zhuo

zhuoyh@mail.sysu.edu.cn

Yiqing $\mathrm{Li}$

liyiqing3@mail.sysu.edu.cn

Specialty section:

This article was submitted to

Ophthalmology,

a section of the journal

Frontiers in Medicine

Received: 07 June 2021 Accepted: 01 November 2021 Published: 23 November 2021

Citation:

Luo M, Li Y and Zhuo Y (2021) Advances and Current Clinical Applications of Anterior Segment Optical Coherence Tomography Angiography. Front. Med. 8:721442.

doi: 10.3389/fmed.2021.721442

\section{Advances and Current Clinical Applications of Anterior Segment Optical Coherence Tomography Angiography}

\author{
Man Luo, Yiqing Li* and Yehong Zhuo*
}

State Key Laboratory of Ophthalmology, Zhongshan Ophthalmic Center, Sun Yat-sen University, Guangdong Provincial Key Laboratory of Ophthalmology and Visual Science, Guangzhou, China

Optical coherence tomography angiography (OCTA) is the most relevant evolution based on optical coherence tomography (OCT). OCTA can present ocular vasculature, show detailed morphology for assessment, and quantify vessel parameters without intravenous dye agent. Research on the anterior segment OCTA (AS-OCTA) is only in its initial phase, and its advances in clinical diagnosis and treatment efficacy evaluations require a detailed comparison to traditional imaging methods. In this review of AS-OCTA, we summarize its technical features, imaging advances, current clinical applications in various eye diseases, as well as its limitations and potential future directions. AS-OCTA offers potential advantages in ophthalmic imaging, and with further development it could become a common tool in the near future.

Keywords: optical coherence tomography angiography, anterior segment, vascularization, clinical application, clinical diagnosis, efficacy evaluation

\section{INTRODUCTION}

Optical coherence tomography (OCT) provides a non-invasive and rapid way to image the eye in vivo. In the early 1990s, OCT was introduced to display retinal structures in cross-sections, such as the macula and optic nerve. Simultaneously, quantitative parameters of retina can also be detected, such as the peripapillary nerve fiber layer thickness, which is specifically identified in the development of open angle glaucoma $(1,2)$. With continuous development over the last 10 years, a new form of angiography, known as OCT angiography (OCTA), has been created (3). As the most relevant evolution of OCT, OCTA evaluates tissue from morphology to the study of functional components without intravenous injection of dye $(4,5)$. OCTA was designed for the posterior ocular segment, and has been widely used in age-related macular degeneration, high myopia, retinal vascular diseases, inflammatory diseases, and optic nerve diseases $(2,6,7)$. OCTA allows better discrimination of the foveal avascular zone and parafoveal microvasculature than fluorescence angiography (FA), and can detect changes in lesions and early recurrence, even before the exudation detected on OCT (8-12). OCTA has improved identification of capillary nonperfusion, microaneurysms, and retinal ischemia, as well as delineating the foveal avascular zone $(11,13-22)$.

Most recently, a growing number of studies have been focusing on OCTA for anterior segment diseases. Anterior segment OCTA (AS-OCTA) provides a novel technique for acquiring anterior segment vasculature images (23). Although research on AS-OCTA is only in its initial phase, it has been gaining attention and recognition $(7,24,25)$. Therefore, the application of AS-OCTA in clinical diagnosis and treatment needs to be summarized. 
AS-OCTA offers several advantages over traditional angiography. Its non-invasive nature and rapid inspection time allow frequent repetition of tests, and avoids the potential risks of dye-based angiography (5). In addition, AS-OCTA provides cross-sectional high-resolution images of the vasculature and allows for analysis according to depth located on a specific axis $(7,26)$. It is also a more cost-effective method over conventional angiography that is more time-consumable and requires training-certified clinicians $(24,27)$.

Slit-lamp photography is the most common method for capturing anterior segment vasculature. However, the results of slit-lamp photography are easily influenced by corneal transparency and background iris vessels $(24,28)$. Dye-based techniques, including FA and indocyanine green angiography, are applied to assess vessels clinically $(2,24)$. However, dye administration is not suitable for some patients, and has various contraindications (2, 27-29). AS-OCT has advanced as a useful tool in providing rapid, non-contact evaluation of the anterior segment, and it takes a vital role in diagnosing and monitoring the effect of therapy in anterior segment diseases (30-32). However, AS-OCTA has developed the imaging technologies for increasing the speed and image resolution. Moreover, it offers the technology of evaluation of vascular flow (33). Furthermore, with the development of anti-angiogenic therapy, non-invasive techniques are needed for quantitative analysis in anterior segment vasculature (25). Because the OCTA systems are designed for posterior diseases, imaging the anterior segment requires putting on an adaptor lens $(24,29,34)$. The quantitative index, including vessel density and blood flow, can monitor the effect of anti-vascular endothelial growth factor (VEGF) treatment, and guide treatment planning and prognostic evaluation $(24,25)$. Thus, an increasing role for AS-OCTA brings more attention and importance (35).

The aim of this review is to summarize the current applications of the AS-OCTA, including the diagnosis, therapy, and prognosis of detailed anterior diseases. In addition, the study discusses the limitations and potential future directions of AS-OCTA.

\section{ACQUISITION AND ANALYSIS OF AS-OCTA}

Different types of devices have been reported in AS-OCTA scanning (e.g., AngioVue, DRI Triton, and PLEX Elite 9000). The majority of the studies use adaptor lens, and manually adjust the equipment parameters $\mathrm{F}$ and $\mathrm{Z}$ for anterior segment imaging ( $\mathrm{F}$ was adjusted to the minimum value and $\mathrm{Z}$ was close to the maximum) (36-41). During the whole scanning process, the external lens has been put near the eye, so we need to pay special attention during the inspection process to avoid damage (42). Some studies haven't used adaptor lens, applied the retina scanning procedure and manually adjusted the $\mathrm{F}$ value to the maximum value $(39,43)$. According to the anatomical structure of the eye, the diopter of posterior segment differs by $20 \mathrm{D}$ (diopters) from that of anterior segment (42). A self-designed lens holder was made by 3 Dimensions printing technology, which could place a $35 \mathrm{D}$ biconvex lens provided by Heidelberg at a suitable distance about $2 \mathrm{~mm}$ in front of the retinal lens to obtain an image (42). For the best image quality, the scanning area should be placed within the B scan range as far as possible. To avoid artifacts from the cornea and iris vessels, the scanning position can be placed flipping the zero-delay line and the image can be obtained "upside down" $(39,44)$. It is worth noting that the traditional image quality scoring standard and automatic image slicing function are not recommended in the current methods of obtaining AS-OCTA images (42).

\section{AS-OCTA PRECISE DIAGNOSIS}

\section{Conjunctiva}

A chemical burn can lead to rapid and permanent denaturation to ocular surface (44). AS-OCTA was able to identify the normal vasculature in unaffected areas and areas of ischemia, similar in appearance to FA (45). Additionally, it can detect vascular flow though conjunctival edema and hemorrhages (46). In pterygium, AS-OCTA can detect more abundant vascularization in pterygium than in normal conjunctiva. In addition, these vessels are most obvious in the subepithelial connective tissue. The morphology of these vessels is newly formed, with smaller caliber, tortuous and branched shape, and rarely visible lumen (39). In the remaining connective tissue, the blood vessels have a regular diameter and morphology, very similar to normal conjunctive; their cavities are visible, sometimes dilated, and filled with blood (47). A study of scleral contact lens (ScCL) wearers demonstrates that repeated use of ScCL can cause vascular alterations in conjunctiva detected by AS-OCTA (48). Recent research shows that AS-OCTA works best on superficial and non-pigmented conjunctiva lesions, and malignant lesions always accompanied by deeper and larger perilesional vessels, which could be a significant marker of clinical diagnosis $(49,50)$.

\section{Cornea and Limbus}

Combing structure and vascular information, OCTA can distinctly diagnose corneal pathologies (24-26). In addition, research suggests that AS-OCTA can show early corneal angiogenesis more clearly than slit-lamp photography $(6,24)$. OCTA can detect subtle abnormal blood vessels with corneal opacity, vascularization around the cornea or in front of the iris, which may not be detected by slit-lamp photography $(6,24)$. Both FA and indocyanine green angiography technologies only provide two-dimensional images, and dye leakage may hinder the analysis of deep blood vessels. OCTA allows simultaneous evaluation of the lesion structure and its related vessels in three-dimensions and at any predetermined depth (24). Severe corneal neovascularization (CoNV) always presents thicker, deeper, larger vessels on AS-OCTA (51). It has been noted that the extension and thickness of CoNV is related to the severity of limbal stem cell deficiency (LSCD) and best corrected visual acuity (BCVA) (52). In addition, Varma et al. (53) observed the conjunctivalization of the cornea caused by LSCD. The vascularization concentrated in superficial layer of peripheral cornea is the sign of LSCD, which can be differentiated from deeper vascularization caused by corneal inflammation. 


\section{Ciliary Body and Iris}

OCTA provides a non-invasive method for detecting small capillaries or microaneurysm flow, even at an early stage of neovascularization of the iris without leakage of dye, and only need little adjustments to the OCTA device $(54,55)$. Current assessments for neovascularization of the iris include slit lamp biomicroscopy, gonioscopy, FA, and indocyanine green angiography (56-58). Furthermore, conventional examinations may miss the very fine neovascularization of the iris $(59,60)$. Moreover, the assessment of neovascularization of the iris always needs a non-dilated pupil using dye-based angiography; thus, it is not possible to perform FA and indocyanine green angiography of the iris and retina at the same time, since most cases are caused by ischemic retinopathy (58).

The inflammation in the anterior uveitis always appears primarily on the iris and the ciliary body (3). During the active stage, the vessel in the iris dilates visibly. However, assessment of that presence is limited to previous examination, like fluorescein angiography (59). The reason is that the capillaries are nonfenestrated in the iris, and the leakage caused by inflammation cannot be shown by fluorescein angiography $(59,61)$. Since it is dye-free technology, AS-OCTA may provide more than a just promising method for assessing vascular anomalies in active anterior segment inflammation and para-inflammatory conditions. It might also be a safe and more precise method for investigating the pathophysiology of inflammation and the preclinical therapeutic strategies for uveitis $(39,55)$. Iris cysts appears with no intrinsic vascularity detected by AS-OCTA, and this could become a key imaging feature to distinguish iris cysts from other iris lesions (62).

\section{AS-OCTA FOR EFFICACY FOLLOW-UP Conjunctiva}

The evaluation of limbal epithelial stem cells is related to the severity of the conjunctival chemical burn, therefore a reliable and objective assessment of limbal non-perfusion could make prognosis more accurate (63-65). The range of severe limbal ischemia determined by AS-OCTA represented the severity of LSCD (46). The correlation between AS-OCTA prognosis and visual outcome at 3 months supersedes that of FA. ASOCTA could also be used for longitudinal clinical estimation of recovery and reperfusion (46). En face OCTA can potentially assess the deeper intrascleral vessels, and index the more severe damage that can leads to iris atrophy, cataract, secondary ocular hypertension, or hypotony (46).

Trabeculectomy remains the common surgical procedure for glaucoma when other treatments have failed to control intraocular pressure (66). Fibrosis in the filtering bleb area plays a crucial role in failure of trabeculectomy (67). Hence, an early and objective means of detecting bleb vascularity to minimize fibrosis and lead to better outcomes is important. The Indiana Bleb Appearance Grading Scale and Moorfields Bleb Grading System are clinically used, but these grading systems are quite subjective (68-70). The development in surgical area vascularity and tortuous vessels on bleb are signs of bleb failure $(68,70,71)$. AS-OCTA could be applied to address the early evaluation of bleb, which plays a crucial role in discovering the failure of trabeculectomy $(37,38,72-74)$. Bleb vascularity can be examined sensitively; a previous study showed a correlation between the outcome of AS-OCTA and the outcome of previous grading systems (75). AS-OCTA could potentially be used in evaluating vessel parameters pre- and post-trabeculectomy (75). In a recent study, vascularization of the filtering bleb assessed by AS-OCTA at 1-month post-trabeculectomy could predict surgery effects at 6 months post-treatment and provided timely postsurgery intervention for a more successful outcome from the trabeculectomy (37). A study focused on eyedrops finds that the lowering effect of IOP is associated with a lower baseline vessel density detected by AS-OCTA (76).

\section{Cornea and Limbus}

AS-OCTA provides rapid processing and objective assessment of areas for corneal vessel invasion (77). OCTA is also useful for monitoring vascular changes before and after treatment. Furthermore, AS-OCTA allows estimations of the range and the depth of vascularization and fibrosis, such as the penetration of corneal abnormal vessels. This helps in pre-surgery planning, and monitoring of corneal vascularization after surgeries such as keratoplasty, pterygium surgery, and fine-needle diathermy (FND) combined with subconjunctival Ranibizumab (24-26, 78). In patients who received various treatments after graft rejection, AS-OCTA was able to find a significant decrease in the vascularized area after 3 months of treatment, which is consistent with color photographs (79).

\section{Ciliary Body and Iris}

AS-OCTA is not only useful for screening, but also for followingup and assessment of treatments, such as laser or anti-VEGF therapy for neovascularization of the iris. Roberts et al. (55) showed that AS-OCTA provided a new stage for detecting neovascularization of the iris, which is regressed and clinically invisible. Additionally, en face OCTA can non-invasively show the persistent vessels by imaging blood flow after treatment. In the future, longitudinal follow-up will be indispensable for identifying OCTA markers for regression before and after therapy (37).

To better monitor the response to the treatment in clinical trials of anterior uveitis, efforts have been made utilizing multimodal imaging to objectively measure ocular inflammation, for better patient monitoring and response measurement in clinical studies $(80,81)$. OCTA provides a superior objective measurement for showing the capillaries. Pichi et al. (82) showed that the dilatation and increased blood flow of an iris with acute anterior uveitis in OCTA could be recognized and quantified by AS-OCTA. This means that the iris vascular caliber might be a good index for quantifying the presence of inflammation and monitoring response to treatment. Choi et al. (83) compared the vessels caliber at different time points, whereas in the current study, an objective quantification was employed. A case of chronic retinal necrosis (CRN) finds that AS-OCTA can detect non-perfusion area of iris, and the reperfusion during the proper treatment, which could make an accurate follow-up of the progression (84). 
TABLE 1 | Advantages and applications of AS-OCTA.

\begin{tabular}{|c|c|c|}
\hline & Precise diagnosis & Efficacy evaluation \\
\hline \multirow[t]{3}{*}{ Conjunctiva } & $\begin{array}{l}\text { Identification of abnormal vasculature areas and conjunctival } \\
\text { lesions }\end{array}$ & Longitudinal estimation of reperfusion \\
\hline & Detection of deeper intrascleral vessels & $\begin{array}{l}\text { Early evaluation of blood flow density on filtering bleb } \\
\text { after trabeculectomy }\end{array}$ \\
\hline & Assessment of limbal epithelial stem cell & \\
\hline \multirow[t]{4}{*}{ Cornea and limbus } & Detection of early corneal angiogenesis & $\begin{array}{l}\text { Preoperative surgical planning by evaluating the depth } \\
\text { and area of feeder vessel }\end{array}$ \\
\hline & Detection of subtle abnormal vessels with corneal opacity & $\begin{array}{l}\text { Repeatable evaluation of treatment effect by vascular } \\
\text { progression and regression }\end{array}$ \\
\hline & 3D imaging of cornea layers & Better observation of corneal graft rejection \\
\hline & Scan of predetermined depth of cornea & \\
\hline \multirow[t]{3}{*}{ Ciliary body and iris } & Early detection of small capillaries and microaneurysms flow & $\begin{array}{l}\text { Evaluation of regressed neovascularization of the iris } \\
\text { during anti-VEGF therapy }\end{array}$ \\
\hline & Assessment of vascular anomalies in anterior uveitis & Exposure of persistent neovascularization \\
\hline & Identification of iris lesions & \\
\hline
\end{tabular}

VEGF, vascular endothelial growth factor; 3D, three dimensions.

\section{CURRENT LIMITATION AND FUTURE DIRECTIONS}

Although AS-OCTA has many advantages for clinical applications, its limitations need to be addressed in future AS-OCTA studies. First, the OCTA device and software were designed for the posterior segment; imaging the anterior segment requires putting on an adaptor lens, which may yield lower quality images and inaccurate parameter values. A specific algorithm for anterior imaging with automated adjustment is necessary to improve and standardize the scan quality, such as the automation of focus and scaling $(68,85)$. Secondly, pupil size might affect vasculature caliber and morphological characteristics (39). Although studies have chosen similar lighting conditions, pupil size changes are unavoidable. The need to control the effect of environmental factors that can influence the vasculature in anterior segment should not be ignored; quantitatively reproducible measurements are needed to solve the problem. Thirdly, the conventional technique of OCTA lacks a sequential image matching function, which makes it hard to fix the same area of interest and reduce motion artifacts caused by severely decreased visual acuity. Thus, an eye-tracking system and sequential image matching system need to be incorporated $(24,85)$.

Furthermore, the restriction of the scanning field and signal dropout does not support high-quality imaging of both the perimeter part and the central part of region in interest. ASOCTA evaluates a limited area and depth compared to AS-OCT, which is designed for the external eye. To meet this challenge, ASOCT with angiography technology needs to be developed to help diagnosis and assessment of anterior segment diseases. Moreover, a wide field swept-source OCTA, which is operated at longer wavelengths, might be able to solve this issue $(55,77)$. Currently, wide-field swept-source OCTA provides a wider-angle image for detecting diabetic retinopathy lesions, such as $12 \times 12 \mathrm{~mm}$ or even $15 \times 9 \mathrm{~mm}$ using the Montage technique (86). What's more, wide-field swept-source OCTA shows huge prospects for anterior segment imaging due to its sufficient scanning range and high sensitivity in detecting structures.

\section{CONCLUSION}

The imaging methods of AS-OCTA described here provide a rapid and non-invasive tool for specialized imaging. The technique allows detection of vessel diameter, density, and overall appearance, and provides powerful methods for helping clinical prognoses, diagnoses, and treatment outcomes (Table 1). Moreover, the challenges in AS-OCTA that were presented here should encourage the improvement of future techniques.

\section{AUTHOR CONTRIBUTIONS}

ML, YL, and YZ wrote and edited the manuscript. All authors contributed to the article and approved the submitted version.

\section{FUNDING}

This work was supported by the National Natural Science Foundation of China (81870657, 81870658), the Natural Science Foundation of Guangdong Province (2018A030313049), the Medical Scientific Research Foundation of Guangdong Province (A2018052), and the Fundamental Research Funds for the Youth Scholars of Sun Yat-sen University (18ykpy32).

\section{ACKNOWLEDGMENTS}

We would like to thank Editage (www.editage.cn) for English language editing. 


\section{REFERENCES}

1. Koustenis A Jr, Harris A, Gross J, Januleviciene I, Shah A, Siesky B. Optical coherence tomography angiography: an overview of the technology and an assessment of applications for clinical research. Br J Ophthalmol. (2017) 101:16-20. doi: 10.1136/bjophthalmol-2016-309389

2. Brunner M, Romano V, Steger B, Vinciguerra R, Lawman S, Williams B, et al. Imaging of corneal neovascularization: optical coherence tomography angiography and fluorescence angiography. Invest Ophthalmol Vis Sci. (2018) 59:1263-9. doi: 10.1167/iovs.17-22035

3. Spaide RF, Fujimoto JG, Waheed NK, Sadda SR, Staurenghi G. Optical coherence tomography angiography. Prog Retin Eye Res. (2018) 64:1-55. doi: $10.1016 /$ j.preteyeres.2017.11.003

4. Spaide RF. Volume-rendered optical coherence tomography of diabetic retinopathy pilot study. Am J Ophthalmol. (2015) 160:1200-10. doi: 10.1016/j.ajo.2015.09.010

5. Spaide RF, Fujimoto JG, Waheed NK. Optical coherence tomography angiography. Retina. (2015) 35:2161-2. doi: 10.1097/IAE.0000000000000881

6. Oie Y, Nishida K. Evaluation of corneal neovascularization using optical coherence tomography angiography in patients with limbal stem cell deficiency. Cornea. (2017) 36:S72-5. doi: 10.1097/ICO.00000000000 01382

7. Tan ACS, Tan GS, Denniston AK, Keane PA, Ang M, Milea D, et al. An overview of the clinical applications of optical coherence tomography angiography. Eye. (2018) 32:262-86. doi: 10.1038/eye.2017.181

8. Kuehlewein L, Bansal M, Lenis TL, Iafe NA, Sadda SR, Bonin MA, et al. Optical coherence tomography angiography of type 1 neovascularization in age-related macular degeneration. Am J Ophthalmol. (2015) 160:739-48. doi: 10.1016/j.ajo.2015.06.030

9. Inoue M, Jung JJ, Balaratnasingam C, Dansingani KK, Dhrami-Gavazi E, Suzuki M, et al. A comparison between optical coherence tomography angiography and fluorescein angiography for the imaging of type 1 neovascularization. Investig Ophthalmol Vis Sci. (2016) 57:314-323. doi: $10.1167 /$ iovs. $15-18900$

10. Veronese C, Maiolo C, Morara M, Armstrong GW, Ciardella AP. Optical coherence tomography angiography to assess pigment epithelial detachment. Retina. (2016) 36:645-50. doi: 10.1097/IAE.0000000000000914

11. Soares M, Neves C, Marques IP, Pires I, Schwartz C, Costa MA, et al. Comparison of diabetic retinopathy classification using fluorescein angiography and optical coherence tomography angiography. $\mathrm{Br} J$ Ophthalmol. (2017) 101:62-8. doi: 10.1136/bjophthalmol-2016-309424

12. Tan ACS, Dansingani KK, Yannuzzi LA, Sarraf D, Freund KB. Type 3 Neovascularization imaged with cross-sectional and en face optical coherence tomography angiography. Retina. (2017) 37:234-46. doi: 10.1097/IAE.0000000000001343

13. de Castro-Abeger AH, de Carlo TE, Duker JS, Baumal CR. Optical coherence tomography angiography compared to fluorescein angiography in branch retinal artery occlusion. Ophthalmic Surg Lasers Imaging Retina. (2015) 46:1052-4. doi: 10.3928/23258160-20151027-12

14. Kashani AH, Lee SY, Moshfeghi A, Durbin MK, Puliafito CA. Optical coherence tomography angiography of retinal venous occlusion. Retina. (2015) 35:2323-31. doi: 10.1097/IAE.0000000000000811

15. Cardoso JN, Keane PA, Sim DA, Bradley P, Agrawal R, Addison PK, et al. Systematic evaluation of optical coherence tomography angiography in retinal vein occlusion. Am J Ophthalmol. (2016) 163:93-107. doi: 10.1016/j.ajo.2015.11.025

16. Coscas F, Glacet-Bernard A, Miere A, Caillaux V, Uzzan J, Lupidi M, et al. Optical coherence tomography angiography in retinal vein occlusion: evaluation of superficial and deep capillary plexa. Am J Ophthalmol. (2016) 161:160-71. doi: 10.1016/j.ajo.2015.10.008

17. Suzuki N, Hirano Y, Yoshida M, Tomiyasu T, Uemura A, Yasukawa T, et al. (2016). Microvascular abnormalities on optical coherence tomography angiography in macular edema associated with branch retinal vein occlusion. Am J Ophthalmol. 161:126-32e1. doi: 10.1016/j.ajo.2015.09.038

18. Dimitrova G, Chihara E, Takahashi H, Amano H, Okazaki K. Quantitative retinal optical coherence tomography angiography in patients with diabetes without diabetic retinopathy. Investig Ophthalmol Vis Sci. (2017) 58:190-6. doi: $10.1167 /$ iovs.16-20531
19. Iafe N, Falavarjani KG, Hubschman, JP, Tsui I, Sadda SR, Sarraf D. (2017). Optical coherence tomography angiography analysis of the foveal avascular zone and macular vessel density after anti-VEGF therapy in eyes with diabetic macular edema and retinal vein occlusion. Investig Ophthalmol Vis Sci. 58:304. doi: $10.1167 /$ iovs.16-20579

20. Krawitz BD, Mo S, Geyman LS, Agemy SA, Scripsema NK, Garcia PM, et al. Acircularity index and axis ratio of the foveal avascular zone in diabetic eyes and healthy controls measured by optical coherence tomography angiography. Vision Res. (2017) 139:177-86. doi: 10.1016/j.visres.2016.09.019

21. Singh A, Agarwal A, Mahajan S, Karkhur S, Singh R, Bansal R, et al. Morphological differences between optic disc collaterals and neovascularization on optical coherence tomography angiography. Graefes Arch Clin Exp Ophthalmol. (2017) 255:753-9. doi: 10.1007/s00417-016-3565-X

22. Kadomoto S, Muraoka Y, Ooto S, Miwa Y, Iida Y, Suzuma K, et al. Evaluation of macular ischemia in eyes with branch retinal vein occlusion an optical coherence tomography angiography study. Retina. (2018) 38:272-82. doi: 10.1097/IAE.0000000000001541

23. Ang M, Devarajan K, Das S, Stanzel T, Tan A, Girard M, et al. Comparison of anterior segment optical coherence tomography angiography systems for corneal vascularisation. Br J Ophthalmol. (2018) 102:873-7. doi: 10.1136/bjophthalmol-2017-311072

24. Ang M, Sim DA, Keane PA, Sng CCA, Egan CA, Tufail A, et al. Optical coherence tomography angiography for anterior segment vasculature imaging. Ophthalmology. (2015) 122:1740-7. doi: 10.1016/j.ophtha.2015.05.017

25. Ang M, Cai YJ, Shahipasand S, Sim DA, Keane PA, Sng CCA, et al. En face optical coherence tomography angiography for corneal neovascularisation. $\mathrm{Br}$ J Ophthalmol. (2016) 100:616-21. doi: 10.1136/bjophthalmol-2015-307338

26. Ang M, Tan ACS, Cheung CMG, Keane PA, Dolz-Marco R, Sng CCA, et al. Optical coherence tomography angiography: a review of current and future clinical applications. Graefes Arch Clin Exp Ophthalmol. (2018) 256:237-45. doi: 10.1007/s00417-017-3896-2

27. Cai YJ, del Barrio JLA, Wilkins MR, Ang M. (2017). Serial optical coherence tomography angiography for corneal vascularization. Graefes Arch Clin Exp Ophthalmol. 255:135-9. doi: 10.1007/s00417-016-3505-9

28. Stenzel TP, Devarajan K, Lwin NC, Yam GH, Schmetterer L, Mehta JS, et al. Comparison of optical coherence tomography angiography to indocyanine green angiography and slit lamp photography for corneal vascularization in an animal model. Sci Rep. (2018) 8:11493. doi: 10.1038/s41598-018-29752-5

29. Ang M, Cai YJ, MacPhee B, Sim DA, Keane PA, Sng CCA, et al. Optical coherence tomography angiography and indocyanine green angiography for corneal vascularisation. $\mathrm{Br} J$ Ophthalmol. (2016) 100:1557-63. doi: 10.1136/bjophthalmol-2015-307706

30. Ang M, Chong W, Tay WT, Yuen L, Wong TY, He MG, et al. Anterior segment optical coherence tomography study of the cornea and anterior segment in adult ethnic south asian indian eyes. Investig Ophthalmol Vis Sci. (2012) 53:120-5. doi: 10.1167/iovs.11-8386

31. Ang M, Chong W, Huang HQ, Tay WT, Wong TY, He MG, et al. (2013). Comparison of anterior segment optical tomography parameters measured using a semi-automatic software to standard clinical instruments. PLOS ONE. 8:e65559. doi: 10.1371/journal.pone.0065559

32. Venkateswaran N, Galor A, Wang JH, Karp CL. Optical coherence tomography for ocular surface and corneal diseases: a review. Eye Vis. (2018) 5:13. doi: 10.1186/s40662-018-0107-0

33. Spaide RF, Klancnik J, Cooney MJ. Retinal vascular layers imaged by fluorescein angiography and optical coherence tomography angiography. JAMA Ophthalmol. (2015) 133:45-50. doi: 10.1001/jamaophthalmol.2014.3616

34. Ang M, Baskaran M, Werkmeister RM, Chua J, Schmidl D, dos Santos VA, et al. Anterior segment optical coherence tomography. Prog Retin Eye Res. (2018) 66:132-56. doi: 10.1016/j.preteyeres.2018.04.002

35. Lee WD, Devarajan K, Chua J, Schmetterer L, Mehta JS, Ang M. Optical coherence tomography angiography for the anterior segment. Eye Vis. (2019) 6:4. doi: 10.1186/s40662-019-0129-2

36. Akagi T, Uji A, Huang AS, Weinreb RN, Yamada T, Miyata M, et al. Conjunctival and intrascleral vasculatures assessed using anterior segment optical coherence tomography angiography in normal eyes. Am J Ophthalmol. (2018) 196:1-9. doi: 10.1016/j.ajo.2018.08.009 
37. Yin X, Cai QH, Song R, He XF, Lu PR. Relationship between filtering bleb vascularization and surgical outcomes after trabeculectomy: an optical coherence tomography angiography study. Graefes Arch Clin Exp Ophthalmol. (2018) 256:2399-405. doi: 10.1007/s00417-018-4136-0

38. Hayek S, Labbe A, Brasnu E, Hamard P, Baudouin C. Optical coherence tomography angiography evaluation of conjunctival vessels during filtering surgery. Transl Vis Sci Technol. (2019) 8:4. doi: 10.1167/tvst.8.4.4

39. Pichi F, Roberts P, Neri P. The broad spectrum of application of optical coherence tomography angiography to the anterior segment of the eye in inflammatory conditions: a review of the literature. J Ophthalmic Inflamm Infect. (2019) 9:18. doi: 10.1186/s12348-019-0184-9

40. Seo JH, Lee Y, Shin JH, Kim YA, Park KH. Comparison of conjunctival vascularity changes using optical coherence tomography angiography after trabeculectomy and phacotrabeculectomy. Graefes Arch Clin Exp Ophthalmol. (2019) 257:2239-55. doi: 10.1007/s00417-019-04412-0

41. Siddiqui Y, Yin J. Anterior segment applications of optical coherence tomography angiography. Semin Ophthalmol. (2019) 34:264-9. doi: 10.1080/08820538.2019.1620805

42. Ayres M, Smallwood R, Brooks AM, Chan E, Fagan X. Anterior segment optical coherence tomography angiography. J Vis Commun Med. (2019) 42:153-7. doi: 10.1080/17453054.2019.1631122

43. Mastropasqua R, Brescia L, Di Antonio L, Guarini D, Giattini D, Zuppardi E, et al. Angiographic biomarkers of filtering bleb function after XEN gel implantation for glaucoma: an optical coherence tomography-angiography study. Acta Ophthalmol. (2020) 98:e761-7. doi: 10.1111/aos.14371

44. Wagoner MD. Chemical injuries of the eye: current concepts in pathophysiology and therapy. Surv Ophthalmol. (1997) 41:275-313. doi: 10.1016/S0039-6257(96)00007-0

45. Kuckelkorn R, Remky A, Wolf S, Reim M, Redbrake C. Video fluorescein angiography of the anterior eye segment in severe eye burns. Acta Ophthalmol Scand. (1997) 75:675-80. doi: 10.1111/j.1600-0420.1997.tb00629.x

46. Fung SSM, Stewart RMK, Dhallu SK, Sim DA, Keane PA, Wilkins $\mathrm{MR}$, et al. Anterior segment optical coherence tomographic angiography assessment of acute chemical injury. Am J Ophthalmol. (2019) 205:165-74. doi: 10.1016/j.ajo.2019.04.021

47. Liu YC, Devarajan K, Tan TE, Ang M, Mehta JS. Optical coherence tomography angiography for evaluation of reperfusion after pterygium surgery. Am J Ophthalmol. (2019) 207:151-8. doi: 10.1016/j.ajo.2019.04.003

48. Jesus J, Dias L, Almeida I, Costa T, Chibante-Pedro J. Analysis of conjunctival vascular density in scleral contact lens wearers using optical coherence tomography angiography. Cont Lens Anterior Eye. (2021) 101403. doi: 10.1016/j.clae.2020.12.066. [Epub ahead of print].

49. Binotti WW, Mills H, Nose RM, Wu HK, Duker JS, Hamrah P. Anterior segment optical coherence tomography angiography in the assessment of ocular surface lesions. Ocul Surf. (2021) 22:86-93. doi: 10.1016/j.jtos.2021.07.009

50. Brouwer NJ, Marinkovic M, Bleeker JC, Luyten GPM, Jager MJ. Anterior segment OCTA of melanocytic lesions of the conjunctiva and iris. Am J Ophthalmol. (2021) 222:137-47. doi: 10.1016/j.ajo.2020.09.009

51. Binotti WW, Koseoglu ND, Nose RM, Kenyon KR, Hamrah P. Novel parameters to assess the severity of corneal neovascularization using anterior segment optical coherence tomography angiography. Am J Ophthalmol. (2021) 222:206-17. doi: 10.1016/j.ajo.2020.08.023

52. Binotti WW, Nose RM, Koseoglu ND, Dieckmann GM, Kenyon K, Hamrah $\mathrm{P}$. The utility of anterior segment optical coherence tomography angiography for the assessment of limbal stem cell deficiency. Ocul Surf. (2021) 19:94-103. doi: 10.1016/j.jtos.2020.04.007

53. Varma S, Shanbhag SS, Donthineni PR, Mishra DK, Singh V, Basu S. Highresolution optical coherence tomography angiography characteristics of limbal stem cell deficiency. Diagnostics (Basel). (2021) 11:1130. doi: 10.3390/diagnostics11061130

54. Gartner S, Henkind P. Neovascularization of the iris (rubeosis iridis). Surv Ophthalmol. (1978) 22:291-312. doi: 10.1016/0039-6257(78)90175-3

55. Roberts PK, Goldstein DA, Fawzi AA. Anterior segment optical coherence tomography angiography for identification of iris vasculature and staging of iris neovascularization: a pilot study. Curr Eye Res. (2017) 42:1136-42. doi: $10.1080 / 02713683.2017 .1293113$
56. Parodi MB, Bondel E, Russo D, Ravalico G. Iris indocyanine green videoangiography in diabetic iridopathy. Br J Ophthalmol. (1996) 80:416-9. doi: $10.1136 /$ bjo.80.5.416

57. Brancato R, Bandello F, Lattanzio R. Iris fluorescein angiography in clinical practice. Surv Ophthalmol. (1997) 42:41-70. doi: 10.1016/S0039-6257(97)84042-8

58. Sivak-Callcott JA, O'Day DM, Gass JD, Tsai JC. Evidence-based recommendations for the diagnosis and treatment of neovascular glaucoma. Ophthalmology. (2001) 108:1767-76. doi: 10.1016/S0161-6420(01)00775-8

59. Bandello F, Brancato R, Lattanzio R, Falcomata B, Malegori A. Biomicroscopy versus fluorescein angiography of the iris in the detection of diabetic iridopathy. Graefes Arch Clin Exp Ophthalmol. (1993) 231:444-8. doi: 10.1007/BF02044229

60. Li ZQ, Zhou XX, Lin S, Li JL, Wu JG. Angiography reveals early hiding iris neovascularization after ischemic CRVO. Int J Ophthalmol. (2013) 6:253-4. doi: 10.3980/j.issn.2222-3959.2013.02.28

61. Danzig CJ, Shields CL, Mashayekhi A, Ehya H, Manquez ME, Shields JA. Fluorescein angiography of iris juvenile xanthogranuloma. J Pediatr Ophthalmol Strabismus. (2008) 45:110-2. doi: 10.3928/01913913-20080301-03

62. Kose HC, Gunduz K, Hosal MB. Iris Cysts: Clinical features, imaging findings, and treatment results. Turk J Ophthalmol. (2020) 50:31-6. doi: 10.4274/tjo.galenos.2019.20633

63. Roper-Hall MJ. Thermal and chemical burns. Trans Ophthalmol Soc U K. (1965) 85:631-53.

64. Dua HS, King AJ, Joseph A. A new classification of ocular surface burns. $\mathrm{Br} J$ Ophthalmol. (2001) 85:1379-83. doi: 10.1136/bjo.85.11.1379

65. Bagley DM, Casterton PL, Dressler WE, Edelhauser HF, Kruszewski FH, McCulley JP, et al. Proposed new classification scheme for chemical injury to the human eye. Regul Toxicol Pharmacol. (2006) 45:206-13. doi: 10.1016/j.yrtph.2006.04.005

66. Cairns JE. Trabeculectomy. Preliminary report of a new method. Am J Ophthalmol. (1968) 66:673-9. doi: 10.1016/0002-9394(68)91288-9

67. Landers J, Martin K, Sarkies N, Bourne R, Watson P. A Twenty-year followup study of trabeculectomy: risk factors and outcomes. Ophthalmology. (2012) 119:694-702. doi: 10.1016/j.ophtha.2011.09.043

68. Cantor LB, Mantravadi A, WuDunn D, Swamynathan K, Cortes A. Morphologic classification of filtering Blebs after glaucoma filtration surgery: The Indiana bleb appearance grading scale. J Glaucoma. (2003) 12:266-71. doi: 10.1097/00061198-200306000-00015

69. Crowston JG, Kirwan JF, Wells A, Kennedy C, Murdoch IE. Evaluating clinical signs in trabeculectomized eyes. Eye. (2004) 18:299-303. doi: $10.1038 /$ sj.eye. 6700638

70. Wells AP, Crowston JG, Marks J, Kirwan JF, Smith G, Clarke JCK, et al. A pilot study of a system for grading of drainage blebs after glaucoma surgery. $J$ Glaucoma. (2004) 13:454-60. doi: 10.1097/00061198-200412000-00005

71. Picht G, Grehn F. Classification of filtering blebs in trabeculectomy: biomicroscopy and functionality. Curr Opin Ophthalmol. (1998) 9:2-8. doi: 10.1097/00055735-199804000-00002

72. Leung CK, Yick DW, Kwong YY, Li FC, Leung DY, Mohamed S, et al. Analysis of bleb morphology after trabeculectomy with Visante anterior segment optical coherence tomography. Br J Ophthalmol. (2007) 91:340-4. doi: 10.1136/bjo.2006.100321

73. Jia YL, Wei E, Wang XG, Zhang XB, Morrison JC, Parikh M, et al. Optical coherence tomography angiography of optic disc perfusion in glaucoma. Ophthalmology. (2014) 121:1322-32. doi: 10.1016/j.ophtha.2014.01.021

74. Watson P, Romano A. The impact of new methods of investigation and treatment on the understanding of the pathology of scleral inflammation. Eye. (2014) 28:915-30. doi: 10.1038/eye.2014.110

75. Seo JH, Kim YA, Park KH, Lee Y. Evaluation of functional filtering bleb using optical coherence tomography angiography. Transl Vis Sci Technol. (2019) 8:14. doi: $10.1167 /$ tvst.8.3.14

76. Akagi T, Okamoto Y, Kameda T, Suda K, Nakanishi H, Miyake M, et al. Short-term effects of different types of anti-glaucoma eyedrop on the scleroconjunctival vasculature assessed using anterior segment OCTA in normal human eyes: a pilot study. J Clin Med. (2020) 9:4016. doi: 10.3390/jcm9124016

77. Kirwan RP, Zheng YL, Tey A, Anijeet D, Sueke H, Kaye SB. Quantifying changes in corneal neovascularization using fluorescein 
and indocyanine green angiography. Am J Ophthalmol. (2012) 154:850-8. doi: 10.1016/j.ajo.2012.04.021

78. Foo VHX, Ke M, Tan CQL, Schmetterer L, Mehta JS, Ang M. anterior segment optical coherence tomography angiography assessment of corneal vascularisation after combined fine-needle diathermy with subconjunctival ranibizumab: a pilot study. Adv Ther. (2021) 38:4333-43. doi: 10.1007/s12325-021-01849-w

79. Harun S, Srinivasan S, Hollingworth K, Batterbury M, Kaye S. Modification of classification of ocular chemical injuries. Br J Ophthalmol. (2004) 88:1353-4. doi: 10.1136/bjo.2004.046797/047308

80. Li Y, Lowder C, Zhang XB, Huang D. Anterior chamber cell grading by optical coherence tomography. Investig Ophthalmol Vis Sci. (2013) 54:258-65. doi: 10.1167/iovs.12-10477

81. Sharma S, Lowder CY, Vasanji A, Baynes K, Kaiser PK, Srivastava SK. Automated analysis of anterior chamber inflammation by spectraldomain optical coherence tomography. Ophthalmology. (2015) 122:1464-70. doi: 10.1016/j.ophtha.2015.02.032

82. Pichi F, Sarraf D, Arepalli S, Lowder CY, Cunningham ET Jr, Neri P, et al. (2017). The application of optical coherence tomography angiography in uveitis and inflammatory eye diseases. Prog Retin Eye Res. 59:178-201. doi: 10.1016/j.preteyeres.2017.04.005

83. Choi WJ, Pepple KL, Zhi ZW, Wang RK.Optical coherence tomography based microangiography for quantitative monitoring of structural and vascular changes in a rat model of acute uveitis in vivo: a preliminary study. J Biomed Optics. (2015) 20:016015. doi: 10.1117/1.JBO.20.1. 016015

84. Zicarelli F, Parrulli S, Torre A, Oldani M, Invernizzi A. Optical coherence tomography angiography findings of iris ischemia and reperfusion in cytomegalovirus panuveitis. Ocul Immunol Inflamm. doi: 10.1080/09273948.2021.1916041

85. Akagi T, Uji A, Okamoto Y, Suda K, Kameda T, Nakanishi H, et al. Anterior segment optical coherence tomography angiography imaging of conjunctiva and intrasclera in treated primary open-angle glaucoma. Am J Ophthalmol. (2019) 208:313-22. doi: 10.1016/j.ajo.2019.05.008

86. Zhu Y, Cui Y, Wang JC, Lu YF, Zeng R, Katz R, et al. Different scan protocols affect the detection rates of diabetic retinopathy lesions by wide-field sweptsource optical coherence tomography angiography. Am J Ophthalmol. (2020) 215:72-80. doi: 10.1016/j.ajo.2020.03.004

Conflict of Interest: The authors declare that the research was conducted in the absence of any commercial or financial relationships that could be construed as a potential conflict of interest.

Publisher's Note: All claims expressed in this article are solely those of the authors and do not necessarily represent those of their affiliated organizations, or those of the publisher, the editors and the reviewers. Any product that may be evaluated in this article, or claim that may be made by its manufacturer, is not guaranteed or endorsed by the publisher.

Copyright $\odot 2021$ Luo, Li and Zhuo. This is an open-access article distributed under the terms of the Creative Commons Attribution License (CC BY). The use, distribution or reproduction in other forums is permitted, provided the original author(s) and the copyright owner(s) are credited and that the original publication in this journal is cited, in accordance with accepted academic practice. No use, distribution or reproduction is permitted which does not comply with these terms. 